of the alley. The object of this secondary railway is to carry the smaller carriages, on which are mounted the actual experimental apparatus of different kinds; so that these may be adjusted on this railway to any desired position fore and aft on the main carriage. The carriage is driven by means of wire rope from a stationary $10^{\prime \prime}$ Tower spherical engine, a high power being required so as to start the truck quickly for high speed experiments. The ordinary speeds range between 100 and 500 feet per minute ; for some classes of models experiments are occasionally made up to about 850 feet per minute or nine and a half miles per hour. The truck has been run at over 1200 feet per minute, or about fourteen miles per hour. The governor, by which the speed of the engine is regulated, is a very interesting and ingenious piece of mechanism, which has been modified from the design of that which was used on the engine at Torquay. There are two symmetrical bell-cranks carrying weights, and attached to each other by links, having slotted holes so as to allow the bell-cranks to have a very small range of freedom of angular motion. When a given speed of rotation is reached, the centrifugal force of the weights overcomes the tension of a spiral spring, provided for the purpose, and the governing action is brought into play in the following manner:-There is a hooked rod, by means of which the increase in the angular altitude of the weights (due to centrifugal force) brings a friction disc break into play, wbich in turn has the effect of extending a spiral spring connected with the engine throttle valve, which is thus closed so as to shut off steam. It will be easily seen how much more delicate an adjustment this device gives than the old Watt governor with the balls acting directly on the valve. The extension of the spring, and the consequent distance of departure of the throttle valve from its full open position are proportional to the frictional turning movement applied to the stationary wheel, which movement is itself proportional to the pressure brought to bear upon it by the bell-cranks; in other words it is proportional to the excess of the speed above that at which the centrifugal force of the weights just equals the tension of the spiral spring. To give greater sensitiveness of action the bell-cranks are not hung on pin joints but on flat springs after the fashion of a clock pendulum, safeguards being provided in case of the springs breaking. With the Torquay governor, which was similar in principle to that described, although differing in appearance, the adjustment was so delicate that a variation of speed in the running of the carriage of half a foot per minute was seldom exceeded even at the highest speeds. The value of working against the resistance of spiral springs will be noticed in this mechanism, their steadying action being especially valuable. It would be impossible for us to attempt to describe the mechanism constituting the copying apparatus of the model shaping machine, and we can only hope to give a mere outline of the general priuciples. A rough hollow model of the ship to be constructed is cast in paraffine wax, a material which is found to lend itself most perfectly to the necessities of the experiments. The drawing from which the operator has to work is stretched on a table, and the grooves representing the water lines are copied from the drawing by means of the mechanism. These grooves are formed by a pair of revolving cutters, the fore and aft motion being communicated to the model whilst the cutters move laterally. One cutter is on each side-for of course full models are required - and they approach or recede symmetrically in such accordance with the longitudinal travel of the model as to trace in plan upon it the intended horizontal section. This due accordance of the lateral motion of the cutters with the longitudinal motion of the model is accomplished by the operator so regulating the cutter motion as to maintain a tracer in contact with the corresponding water-line on the drawing. By suitable mechanism the drawing itself is made to imitate the longitudinal travel of the model, while the tracer imitates the lateral travel of the cutters. In the Torquay machine the tracer was guided by an adjustable template set to the curve of each water-line, but afterwards the tracer was made to follow the line on the drawing by the operator. In the present machine the cutters are raised or lowered to get the different water-lines. The cutters run at 2700 revolutions per minute. The grooves having been cut, the surplus material is removed by hand.

We shall not follow Mr. Froude in his description of the further details of the mechanism, as it would be unintelligible without the drawings by which he illustrated his description. The various arrangements are, however, fully worthy of study by all who are interested in ingenious mechanical devices; but we must refer our readers to the printed transactions of the institution, in which the diagrams will appear when the volume is published. There is also a weighing machine, which is necessary to obtain the actual dead weight of the model, so that the amount of ballast required to get the necessary displacement corresponding to trial draught may be determined. This machine will weigh up to Iooolbs. with great accuracy, and is similar in principle to an ordinary chemical balance, except that it is a steel yard, having one arm 6 inches and the other 5 feet in length.

The discussion on this paper was opened by Mr. W. H. White, the Director of Naval Construction, who is the official head of the Admiralty department, of which the Haslar establishment forms a branch. Mr. White spoke of the advantage these model experiments had been to the navy, saying that the great advance in the speed of ships which had been obtained of late years would not have been reached to the full extent had it not been for the model experiments carried out at Torquay and Haslar by the late Mr. Froude and his son, the author of the paper. MIr. J. I. Thornycroft also pointed out the great economy that had been made in expenditure upon navy ships by finding out teforehand what the proposed vessel would do, and what was required in the way of power to reach that performance. Mr. Thornycroft made especial reference to the ingenuity of the device whereby a line on the drawing, which might not be quite accurate, would be made to give the desired result in the model, and this without an expensivelyconstructed apparatus. Various other speakers having been beard, and Mr. Froude having briefly replied, so far as there was anything to reply to, the meeting adjourned until the next evening.

On the members assembling on Friday evening, the $3^{\text {rd }}$ inst., the president, Dr. Anderson, again occupied the chair, and Mr. Matthews's paper on the Southampton waterworks was read. This contribution is interesting, as it describes what we understand is the largest water-softening plant yet installed. The quantity of water that can be satisfactorily dealt with is from $2 \frac{1}{4}$ to $2 \frac{1}{2}$ million gallons per day of 24 hours. Of course the principle of softening hard water by lime is very far from new, but it has made slow progress, in spite of the vast quantities of hard water, otherwise unobjectionable, that there are in the chalky southern half of our island. 'This limited application of a means whereby a bad water in one respect can be made a good one in all respects does not appsar, to judge by the proceedings of last Friday, to spring from any inherent defect in the system-beyond that which would arise from the disposal of the refuse lime in crowded cities-but rather from the carelessness of public authorities and water-supplying companies to the wants and comforts of the people at large.

The meeting terminated with the usual votes of thanks, the President announcing that the summer meeting would be held this year at Middlesborough on Tuesday, August I, and the following days.

\section{THE SEVEN IMAGES OF THE HUMAN EYE.}

$\mathrm{I} \mathrm{T}$ is well known that in the human eye, besides the refracted image, which serves the purposes of vision, there are formed three reflected images known under the name of "Purkinje's images." M. Tcherning has discovered three additional ones, so that the total number is brought up to seven. ${ }^{1}$

In its passage into the interior of the eye each ray of light has to pass through the cornea, the aqueous humour, the crystalline lens, and the vitreous humour before finally arriving at the retina. At the surface of each of these constituents the ray is liable to be partially reflected, thus giving rise to four reflected images. These were all seen and described by Purkinje at the beginning of the century, kut only three were observed by Helmiholtz and others. These three can be easily observed by two persons on holding a lighted match between their eyes, and moving it about so that the reflections seem to come from the pupil. One of them, that reflected by the front of the cornea, is much brighter than the two others, which are formed by the front surfaces of the crystalline and the vitreous humour respectively. The fourth image is due to reflection from the posterior surface of the cornea. It may be discovered by careful observa. tion of the brightest image by means of a magnifying glass. As r892.

No. 1215 , VOL. 47$]$ 
it approaches the border of the pupil, and especially as it passes on to the iris, it is seen to be accompanied by a small, pale, but well-defined image, which always lies between the first image and the centre of the pupil, the distance between them decreas. ing as they move towards the centre, where they finally coincide. By means of the ophthalmophakometer-an instrument consisting of three incandescent lamps and a telescope arranged on an arc of $86 \mathrm{~cm}$. radius - it was found possible to measure the radii of clirvalure of all the reflectin $r$ surfaces. The foci of the two reflecting surfaces of the cornea were found to coincide, a fact which accounts for the coincidence of the two corresponding images at the centre of the pupil, and for Helmholtz's failure of finding the fainter one.

It is evident that since the light reflected from the successive surfaces does not fall upon the retina, it is lost for visual purposes. But a comparison of the percentages of loss in the case of the eye, and in that of a simple lens tells greatly in favour of the former as an optical instrument. In the eye the percentage of useful light is 97 , in a simple lens 92 , and in a compound optical instrument correspondingly less. But the light reflected by any of the internal surfaces is also liable to be reflected back into the eye or the optical instrument, with the effect of superimposing a more or less faint patch of light upon the image on the retina. This is termed the noxious light (lumière nuisibie) by $M$. Tcherning. In a simple lens this amounts to $\frac{1}{6}$ per cent., whilst in the eye it is as low as 0.002 per cent. But faint as it is, it is capable of giving rise to two light impressions due to double refiection, one at least of which has been actually observed in the human eye. "The easiest way of observing it," says M. Tcherning, "is to look straight forwards in a dark room, holding a lighted candle in the hand about $20 \mathrm{~cm}$. from the line of vision. On moving the candle gently from side to side a pale image of the flame is seen on the opposite side of the line of vision, distinct enough to show that it is inverted; it moves symmetrically to the candle with respect to the line of vision. The rays which form this image have undergone, besides several refractions, two reflections, one at the posterior surface of the crystalline and another at the front surface of the cornea." Another image was expected to be formed by a similar refiection at the anterior surface of the crystalline. It was found in an artificial eye, but not in the human sense-organ. However, an easy calculation of the optical system of the eye explains this circumstance. The focus of the reflected rays is very near the crystalline lens itself, so that they must be much dispersed by the time they reach the retina. To enable the image to be formed on the retina, the object would have to lie between the cornea and the crystalline, but on attempting to form a luminous point at that place by optical means it is found that the "useful rays" fill the eye to such an extent as to render everything else invisible.

It is found that different eyes differ in their capacity of seeing the first of the two additional subjective images. Short-sighted people find it very indistinct unless the candle is held close to the eye, or convex glasses are used. As the maker of optical instruments utilises the accessory images for testing the degree of polish and the accurate centreing of the lenses, so the physician is enabled to make valuable inferences from them as to the structure and condition of the eye he is examining, and the additional images discovered by M. Tcherning appear to be of considerable physiological importance. E. E. F. d'A.

\section{A BOTANIST'S VACATION IN THE HAWAIIAN ISLANDS.}

SOME weeks ago we reprinted from the Botanical Gazette

(Indiana) a part of the first instalment of Prof. D. H. Campbell's interesting account of his vacation in the IIawaiian Islands. The following is the chief portion of the second and concluding instalment, published in the January number :-

Beside visiting the isle of Oahu, I made short trips to the islands of Hawaii and Kauai. The former, the largest of the group, and the only one where volcanic action is still going on, is reached by steamer in about thirty-six hours from Honolulu. On the way, the islands of Molokai, Lanai, and Maui are passed. The first, a barren-looking and forbidding spot, is the location of the leper settlement, to which all persons afflicted with leprosy are sent as soon as their condition becomes known.

NO. I 2 I 5 , vOL. 47]
Maui, the largest of the islands next to Hawaii, consists of two portions connected by a narrow isthmus. The whole eastern half is nuthing more nor less than the body of an immense extinct volcano, ten thousand feet high, and with a crater nearly ten miles across. The other end of the island is an older formation. This island is said to be very interesting botanically; but, unfortunately, my time did not permit me to visit it.

Very soon after sighting Maui, the three great mountain masses of Hawaii began to loom up. The day was clear, and the whole formation of the island became visible. It consists of three great volcanic cones, of which only one is now active. The highest summit, Mauna Kea, is nearly 14,000 feet above the level of the sea; the next, Mauna Loa, lacks but a few hundred feet of this; yet so great is the breadth of these masses that one fails to realise their immense height. Our first landing was at Mahukona, on the leeward side of the island, a most forlorn expanse of bare lava with scarcely a trace of vegetation, except a few unhappy-looking algaroba trees planted about the straggling buildings that constituted the hamlet.

We lay all day at this inhospitable station, not getting away until evening. A beautiful sunset and a fine glimpse of the peak of Mauna Kea glowing with the last rays of the sun, form my most pleasant recollections of this desolate place.

What a change the next morning! On awakening we found ourselves entering the harbour of Hilo. Here everything is as green as can be imagined, and luxuriant vegetation comes down to the very ocean's edge. The town is built on a bay fringed with cocoa-nut trees and embowered in a wealth of tropical vegetation. Owing to the great annual rainfall (about I80 inches), as well as to the fact that Hawaii is the most southerly of the islands, the vegetation here is the most luxuriant and tropical found in the whole group. I remained in Hilo for six days and collected some most interesting specimens. Through the kindness of Mr. Hitchcock of Hilo, I was enabled to spend the night at his camp in the woods near the town, and the greater part of two days collecting in the vicinity. The forest here is most interesting. Mr. Hitcheock was starting a coffee plantation and has cut trails through the woods in several directions, so that collecting was very convenient. There is great danger of glosing one's self in these woods where there are no trails, as much of the forest is an almost impassable jungle. In these moist forests ferns and mosses luxuriate, and every trunk and $\log$ is closely draped with those beautiful growths. Flowers are almost entirely wanting, a fact repeatedly observed by collectors in tropical forests. I saw here fully developed specimens of tree-ferns. The finest of these were species of Cibotium. Many had trunks from fifteen to twenty feet high, and some must have been fully thirty. The most beautiful were some with trunks ten to fifteen feet high, as these were more symmetrical and had fincr fronds than the taller ones. I measured the leaves of one that had fallen over, and roughly estimated the length as eighteen feet. I have no doubt that specimens fully twenty feet long could be found. These giant fronds, arching high over one's head as one rides on horseback under them, present a sight at once unique and beautiful. Growing upon the trunks of these ferns were many epiphytic species, the most peculiar of which was Ophioglossum pendulum, with long strap-shajed leaves, a foot or two long, and a spike of sporangia sometimes six inches long. Exquisite species of Hymenophyllum and Trichomanes, the most ethereal of all the fern tribes, with almost transparent, filmy leaves, were common, sometimes completely enveloping the trunks of the trees. Of the terrestrial ferns, which abounded everywhere, two were especially notable as; representing groups unknown in the United States. One of these, Gleichenia dichotoma, forms extensive thickets on the borders of the forest, and in the Hilo district extends down almost to the sea-level. The other, Marattia Douglasii, a very large fern with leaves eight to ten feet long in well-grown specimens, has fleshy dark green leaves, and thick stipules sheathing the base of the leaf-stalks. Several species of Lycopodium and Selaginella were common, and a good variety of mosses and liverworts. In these forests wild bananas are common, and most magnificent plants they are. Sheltered from the wind, the superb great leaves develop to their full size, without being torn in the least, and the whole plant is a study of beautiful form and colour.

Coffee is being extensively planted in this region as well as upon the lee side of the island, and as the quality of the berry 